\title{
Identification of the "Snowflakes" on the Machined Surface of the AISi10Mg Alloy Casting
}

Jaroslava Svobodová ${ }^{1}$, Milan Luňák ${ }^{1,2}$, Ivan Lukáč ${ }^{3}$

${ }^{1}$ Faculty of Mechanical Engineering, J. E. Purkyně University in Ústí nad Labem. Pasteurova 3334/7, 40090 Ústí nad Labem. Czech Republic. E-mail: jaroslava.svobodova@ujep.cz

${ }^{2}$ BENEŠ a LÁT,a.s. Tovární 463, 28914 Poříčany. E-mail: milan.lunak@benesalat.cz

${ }^{3}$ Material Engineering Department, Technical University of Košice. Letná 9, 04200 Košice. Slovak Republic. E-mail: ivan.lukac@tuke.sk

The usage of aluminium alloys has an increasing trend in the manufacturing industry in recent years. This fact is connected with their ability to combine their very good properties. Characteristics of aluminium are low specific weight, very good thermal and electrical conductivity, and ductility. However, the major disadvantages are low strength and hardness. Therefore the aluminium alloys are alloyed with the elements, which would significantly improve the properties of aluminium. The machining process of aluminium alloys is influenced by many factors that affect the machinability. These factors are for example process conditions, cutting tool material, cutting tool geometry, cutting environment or the chemical composition of the machined material itself and microstructure of the workpiece. Due to the different structures, the machinability of aluminium alloys and pure aluminium is significantly different. Factors such as chemical composition, precipitates, the number and position of soft particles or the strain hardening degree affect the behaviour between the cutting tool and the workpiece during machining. When machining the aluminium alloys, there are some problems such as the surface quality, micro-geometry, tool wear, the chip shape, built-up edge formation, etc. The article deals with the surface defect investigation after the machining process, when on the surface of the material stay the visible "snowflakes" after the turning operation. These "snowflakes" were documented and were performed analysis and observation to find the cause of these flakes.

Keywords: aluminium, AlSi10Mg, machining, surface defect, cutting fluid.

\section{Introduction}

Identification, respectively the classification of the surface defects in aluminium alloys has been and still is paying great attention [1-4]. Mostly it is surface damage due to corrosion processes and a handbook was published for the technical public where the nature of individual surface defects is documented and the cause of their occurrence is described [3]. In castings, surface defects are in many cases due to melting processes [1] but also to crystallization processes $[2,4]$.

Macroscopic determination of the surface defects causes if there is no visible pores resp. cracking is impossible. For the identification and thus the possibility of implementation of technological measures that would prevent the occurrence of the appropriate defect, it is necessary to use modern experimental equipment such as SEM and associated there with ED's analyser. Classical metallography on optical microscopes equipped with appropriate software enabling both qualitative and quantitative evaluation of structural parameters is also important.

If macroscopically visible surface defects occur during mechanical machining, the cause may also be due to the application of a cutting fluid which may cause corrosion processes or due to capillary forces present in microspores.

The present publication focuses on the precise identification of surface defects that have occurred on the machined surface of an AlSi10Mg alloy, whose light morphology resembled the character of "snowflakes".

\section{Sources of aluminium machining problems}

In general, we can say that the basic cause of the defects under discussion is always excessive heat. This may arise directly by frictional heating and/or indirectly by insufficient cooling. The main sources of the aluminium machining problems are:

- cutters (tool geometry must be maintained within the established requirements for aluminium alloys),

- feeds and speeds (depend on the aluminium alloy - chemical composition, microstructure, intermetallic phases, and alloying elements; while the cutting forces during the machining of aluminium alloys are relatively low, they can nevertheless provide a good indicator for a comparison of different alloys under the same machining conditions),

- cutting fluids (an adequate and continuous flow of cutting fluid (flood or mist) directed at the cutting edges is essential; the use of the specific type of cutting fluid depend on the concrete application and type of aluminium alloy),

- support fixtures and clamping methods,

- numerically controlled machining operations,

- Quality control [5, 7].

Although aluminium is relatively easy to machine, optimal performance in chip handling, using of cutting fluid, surface finish and tool life are dependent on several factors. Three factors affect the machinability of aluminium.

- The first factor is the machining process. This factor includes cutting tools, the type of equipment, cutting speeds, feed rates, and lubricants 


\section{- cutting fluids.}

- The second factor involves the material. This factor specifically includes the particular alloy and the temper of the aluminium, its microstructure and the uniformity of its mechanical properties.

- The third factor is the material processing, which involves the chemistry of the aluminium alloy, heat treatment, design and method of the workpiece production.

The machinability of the aluminium alloys depends especially on the Si content. Alloys containing more than $10 \% \mathrm{Si}$ are the most difficult to machine because hard particles of free silicon cause rapid tool wear. Alloys containing more than $5 \% \mathrm{Si}$ will not finish to the bright machined surfaces of other high-strength aluminium alloys but will have slightly grey surfaces with little lustre. Chips are torn rather than sheared from the work, and special measures (such as the use of lubricant-containing cutting fluids) must be taken to avoid the build-up of burrs on cutting edges [5]. Aluminium cast alloys with a high content of silicon, more than $10 \%$, need moderate speeds and small feeds to improve the process economy. This is the case with the Al-Si17 cast alloys. These alloys require the use of lubricants and diamond tools to get good surface qualities $[5,6]$.

The use of cutting fluids in the production of machine parts is common. The cutting fluid has two main functions: lubrication at low cutting speeds and cooling at high cutting speeds. The less important functions are: the help the chip to remove the cutting zone and to protect the machine tool and workpiece against corrosion. This factor - protection against corrosion - it is the subject of our interest due to the experimental part of our article.

The machining of aluminium alloys can be also performed without lubrication (without the use of the cutting fluid). Despite this, the use of cutting fluid is recommended due to the cooling action that will prevent overheating of the tool and the workpiece. The use of cutting fluid also gives a better quality of finished surface [5-7].

Taking into account the chemical effect of the cutting fluid itself from the chemical point of view, the cutting fluid may harm the surface of the material, especially if the cutting fluid remains on the surface after machining. The cutting fluids for aluminium alloys machining can be soluble-oil emulsions, mineral oils, or any aqueous chemical solutions. Cutting oils contain compounds of sulphur or chlorine or the combination of both elements. The literature [5] states that cutting oils are seldom used and are not usually required for machining aluminium. Besides, many of them will stain the workpiece [7].

Due to the occurrence of "snowflakes" on the surface of the material, which is investigated in the experimental part of the paper, we focused mainly on the effect of the cutting fluid, since it is a defect that does not hinder the functionality of the part but has spots visible on the surface, which may, for example, affect the corrosion re- sistance of the part. Based on these findings, we have analysed the material in question and drawn the appropriate conclusions.

\section{Experimental material, results and its analy- sis}

Following the theoretical part of the paper, a practical analysis of the problem has been investigated machine part, which is documented in Figure $1-3$. This machined part is made of AlSi10Mg alloy (EN AC-43100). Aluminium alloy AlSi10Mg is a typical casting alloy with good casting properties. This alloy is typically used for cast parts with thin walls and complex geometry. It offers good strength, hardness and dynamic properties and is therefore also used for parts subject to high loads. Parts made of AlSi10Mg are ideal for applications which require a combination of good thermal properties and low weight. The part can be machined, spark-eroded, welded, micro shot-peened, polished and coated if required. Conventionally cast components in this type of aluminium alloy are often heat treated to improve the mechanical properties, for example using the T6 cycle of solution annealing, quenching and age hardening.

The machine part investigated in our article is used to equalize the pressure of hydraulic fluid in the left and right wheels when braking with the foot hydraulic brake on the tractor. This is a block used in the braking system.

The examined hole is machined with a $19 \mathrm{~mm}$ diameter cannon drill. White spots ("snowflakes", Fig. 3) appeared on the surface of the machined surface after machining, which was the reason for a complaint of the part.

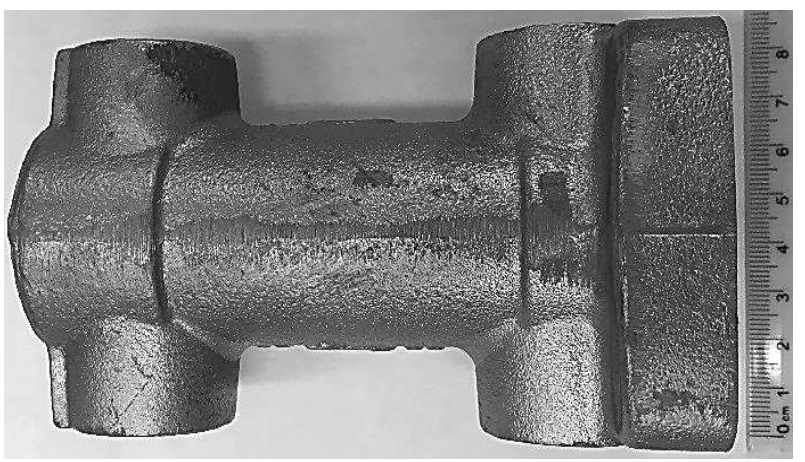

Fig. 1 Examined machine part

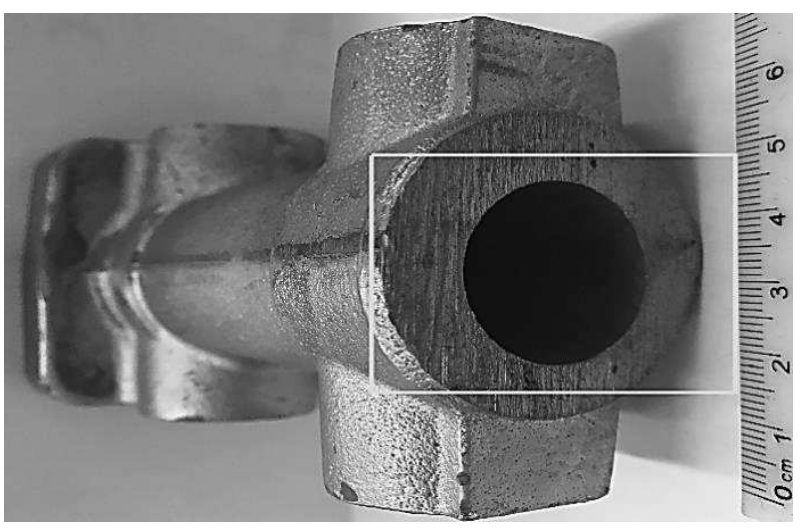

Fig. 2 Examined machine part-machined hole 


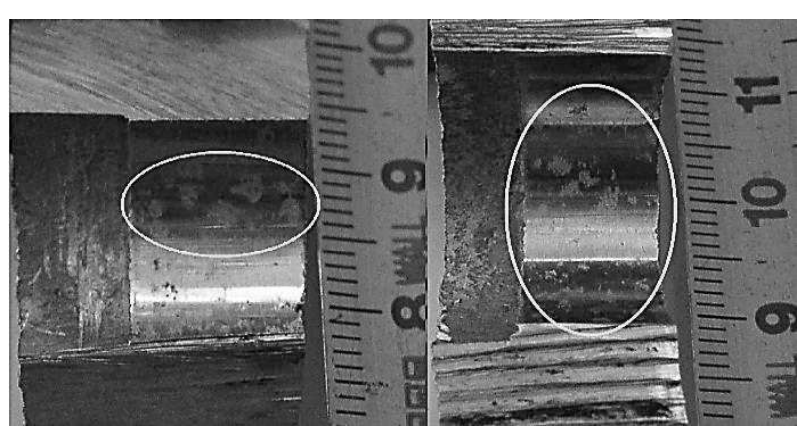

Fig. 3 Detail of the machined hole (the cut-out) - the "snowflakes" on the machined surface
Paramo CUT 32 K 10 cutting fluid is used during machining. It is cutting oil, which contains additives to improve cutting and lubricating effect. Due to their properties, PARAMO CUT cutting oils are suitable for machining common structural and alloy steels, cast iron, cast steel, malleable cast iron, heavy and light non-ferrous metals, as stated by the manufacturer. After machining, the workpieces are not washed in the industry dishwasher. The cutting oil is therefore not removed from the surface and the rest of the oil remains on the surface of the machined hole.

Tab. 1 Chemical composition of the casting

\begin{tabular}{|c|c|c|c|c|c|c|c|c|c|c|c|}
\hline $\begin{array}{c}\text { Ele- } \\
\text { ment }\end{array}$ & $\mathrm{Si}$ & $\mathrm{Fe}$ & $\mathrm{Cu}$ & $\mathrm{Mn}$ & $\mathrm{Mg}$ & $\mathrm{Cr}$ & $\mathrm{Ni}$ & $\mathrm{Zn}$ & $\mathrm{Ti}$ & $\mathrm{Sr}$ & $\mathrm{Al}$ \\
\hline $\begin{array}{c}\text { Content } \\
\text { [wt. \% }\end{array}$ & 10.340 & 0.378 & 0.020 & 0.278 & 0.193 & 0.0045 & 0.0088 & 0.028 & 0.137 & 0.0047 & residue \\
\hline
\end{tabular}

The chemical composition of the casting is shown in the table 1. Chemical composition of the investigated casting agrees with the chemical composition of the alloy listed in the standard ČSN EN 1706. Analysis of the casting chemical composition was performed using optical emission spectrometer Q4 TASMAN.

\subsection{SEM and ED's analysis}

SEM and EDS analysis on TESCAN VEGA 3 electron microscope was used for evaluation of the surface defect (,snowflake") on the machined surface. The white spots are in mm dimension and were well observable on an electron microscope. We performed the EDS analysis at various places of the evaluated sample. Element mapping was carried out as well as area analysis at a selected location respectively in the area of "snowflakes". Various elements have been found on the surface; mainly $\mathrm{C}, \mathrm{F}$, and $\mathrm{Cl}$ are the typical elements for cutting fluids. The results of the SEM and ED's analysis are shown in Table 2 and 3 .



Fig. 4 SEM analysis of the surface defect ("snowflake”)

Tab. 2 ED's analysis (area from the Fig. 5)

\begin{tabular}{|c|c|c|c|c|}
\hline Element & Series & Unn. C [wt. \%] & Norm. C [wt. \%] & Atom. C [at. \%] \\
\hline Carbon & K-series & 69.24 & 69.24 & 76.91 \\
\hline Chlorine & K-series & 1.89 & 1.89 & 0.71 \\
\hline Sulphur & K-series & 0.79 & 0.79 & 0.33 \\
\hline Oxygen & K-series & 23.56 & 23.56 & 19.65 \\
\hline Sodium & K-series & 2.08 & 2.08 & 0.87 \\
\hline Aluminium & K-series & 1.75 & 1.75 & 0.33 \\
\hline Silicon & K-series & 0.69 & 0.69 & 100.00 \\
\hline Total: & - & 100.00 & 100.00 & 0.21 \\
\hline
\end{tabular}



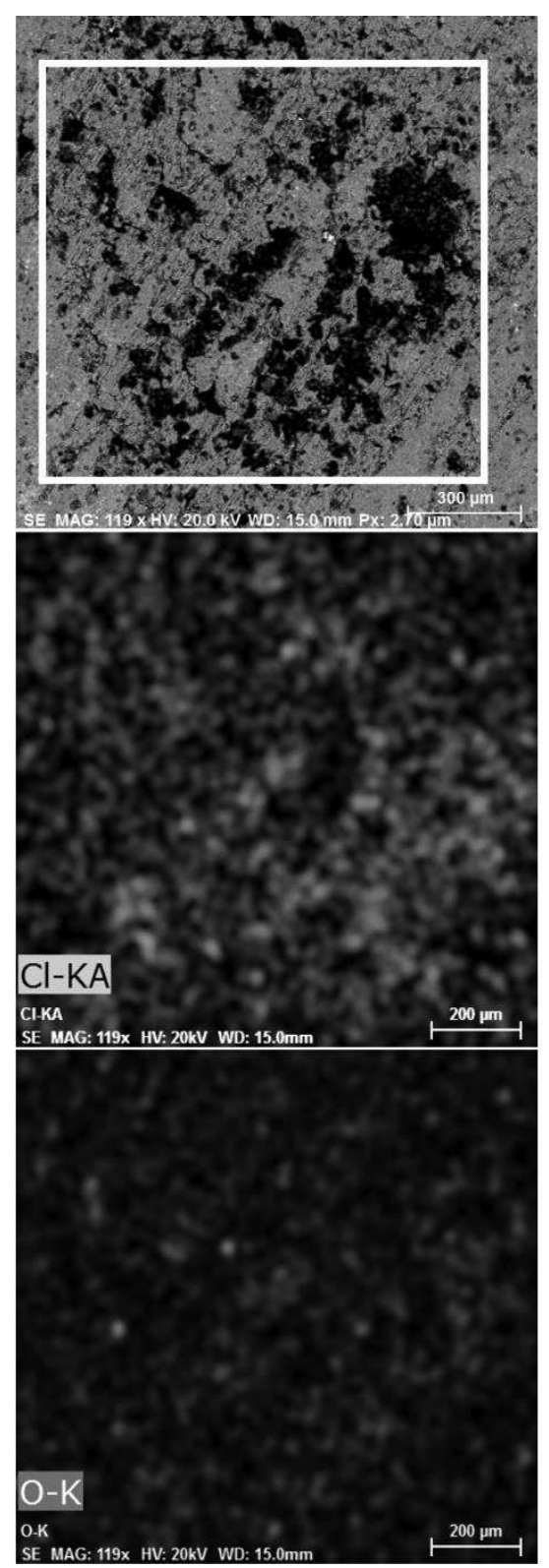
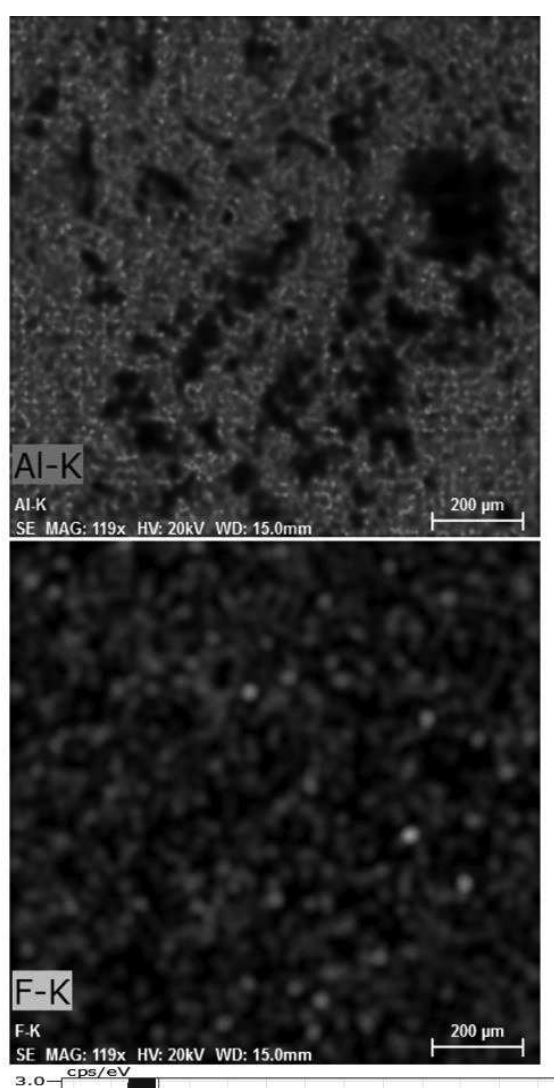

C-K

SE MAG: 119x HV: 20kV WD: $15.0 \mathrm{~m}$
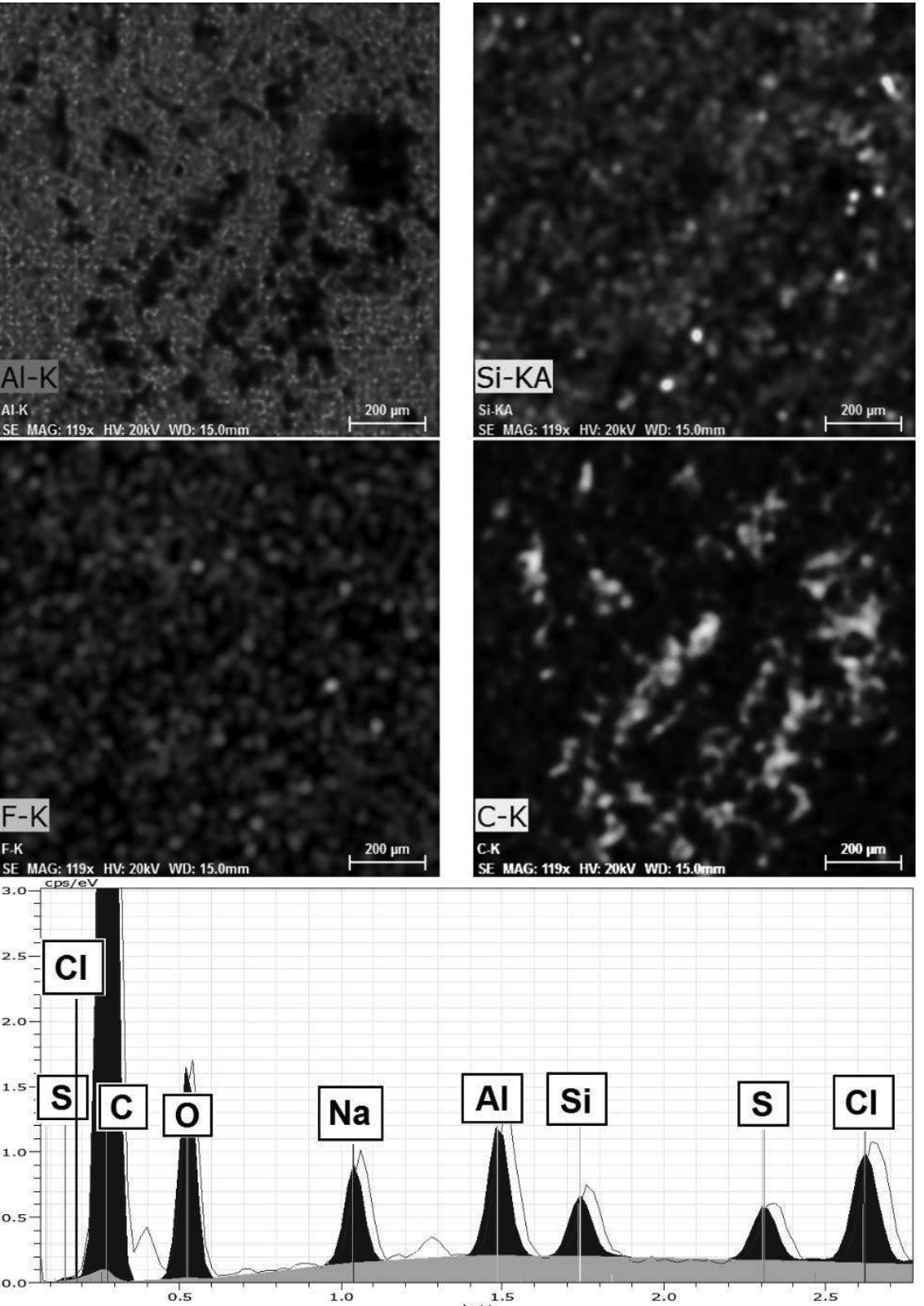

Fig. 5 ED's analysis - elements mapping
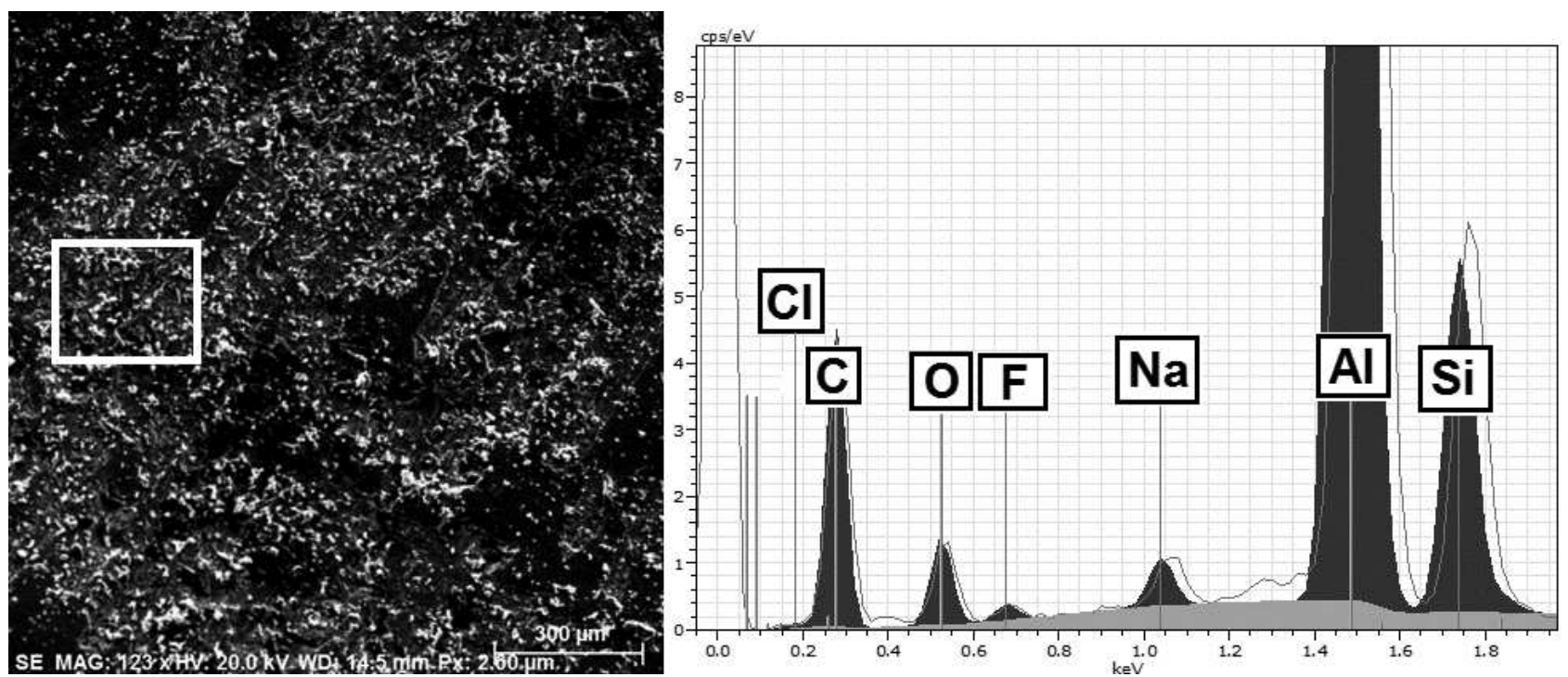

Fig. 6 EDS surface analysis 
Tab. 3 ED's analysis (area from the Fig. 6)

\begin{tabular}{|c|c|c|c|c|}
\hline Element & Series & Unn. C [wt. \%] & Norm. C [wt. \%] & Atom. C [at. \%] \\
\hline Carbon & K-series & 50.58 & 46.31 & 63.66 \\
\hline Chlorine & K-series & 0.63 & 0.58 & 0.27 \\
\hline Fluorine & K-series & 0.92 & 0.84 & 0.73 \\
\hline Oxygen & K-series & 8.85 & 8.11 & 8.36 \\
\hline Sodium & K-series & 0.84 & 0.77 & 0.56 \\
\hline Aluminium & K-series & 41.25 & 37.77 & 23.11 \\
\hline Silicon & K-series & 6.14 & 5.63 & 3.31 \\
\hline Total: & - & 109.22 & 100.00 & 100.00 \\
\hline
\end{tabular}

\subsection{Microscopic analysis}

To obtain complete information about the sample, we also performed an analysis using optical microscopy on the confocal laser microscope OLYMPUS LEXT OLS 3100 as a supplement. From this observation, we can conclude that the sample under investigation has a structure that is typical for the type of AlSi10Mg hypoeutectic aluminium alloy. No defects or surface porosity were observed on the surface of the material, which could be described as causing "snowflakes" (Fig. 7, 8).

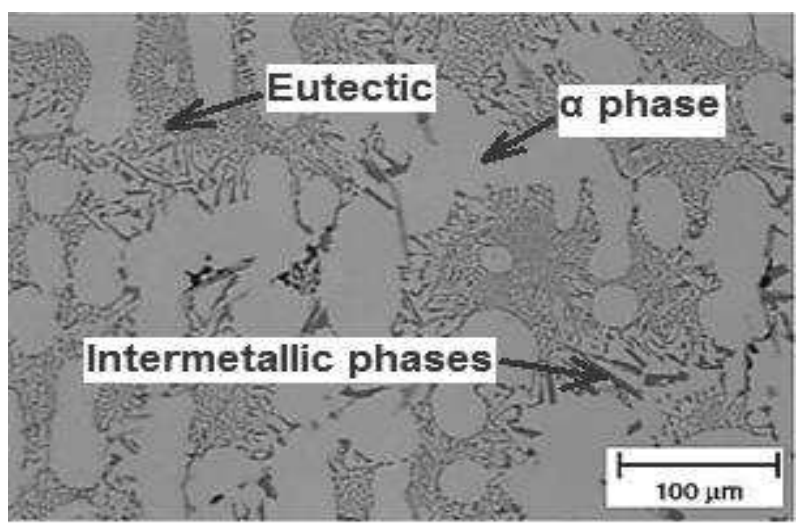

Fig. 7 Microstructure of the investigated sample

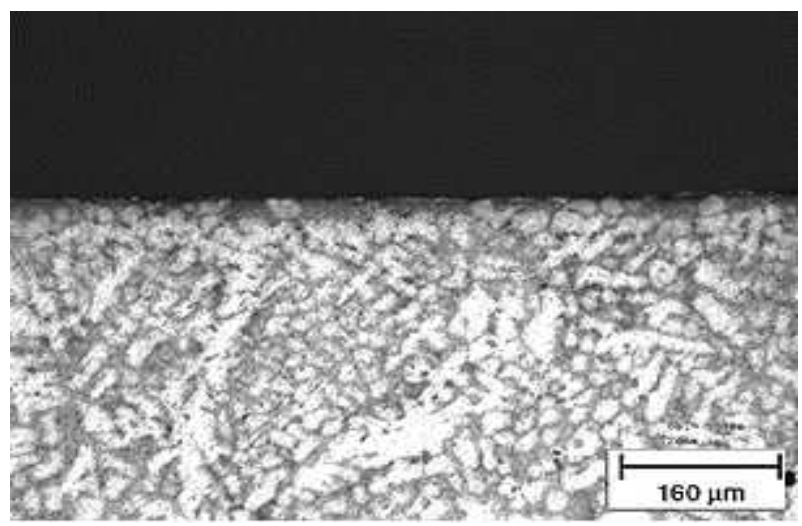

Fig. 8 The investigated sample surface

\section{Conclusion}

This paper deals with the problem of the surface defect after machining. The subject of the investigation is a casting from AlSi10Mg alloy. In this casting, surface defects of white colour appeared on the machined surface (Fig. 2) similar to "snowflakes" in shape and colour. SEM and ED's analysis were performed on the sample; the chemical composition analysis and microscopic analysis were performed as well. Based on acquired knowledge from literature and performed analyses can be stated:

- $\quad$ SEM and EDS analysis - analysis was performed in several places of the sample with similar results. As part of this analysis, we performed element mapping and area analysis. Various elements have been found on the surface, mainly $\mathrm{C}$, $\mathrm{F}$, and $\mathrm{Cl}$. These are typical elements for cutting fluids. Thus, it is not a corrosion attack.

- Spectral analysis of the chemical composition of the material was right. The measured chemical composition of the tested casting corresponds to the chemical composition of the AlSi10Mg alloy according to the standard.

- During the microscopic analysis, we focused on the material microstructure and the sample surface. The sample microstructure is typical for the AlSi10Mg alloy, and no defects (pores, cracks) were found on the sample surface that could be identified as causing "snowflakes".

Performed analyses and knowledges of the given area lead us to the conclusion that the formation of "snowflakes" on the surface of the examined sample is influenced by micro-unevenness of the surface (see schema Fig. 9), in which cutting oil adheres. This is due to a technological fail in the form of the use of unsuitable cutting fluid [7] and failure not to rinse the machined part after machining. Due to the micro-unevenness of the surface, the cutting oil adheres to the surface of the machined surface and, in the absence of rinsing of the workpiece, the cutting oil remains on the machined surface, causing staining.

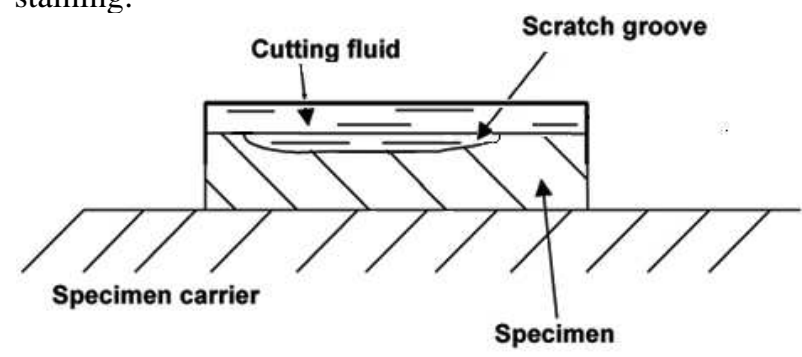

Fig. 9 Schema of the workpiece surface covered by cutting fluid [7] 
The machinability of aluminium alloys depends on a large number of parameters. So it is necessary to select the right (optimal) process conditions for machining these alloys. The studies in the field of aluminium alloys machining provide limited references that do not allow comparable of data and standardization of processes. Aluminium alloys are good materials for machining, except in the case of high-silicon aluminium alloys. For these types of alloy, it is necessary to use special conditions and processes. The solution to problems in machining aluminium alloys can be dry cut, which is also called by researchers ecological machining. Some experts [13, 14] states that either when cutting fluid application is not clearly cheaper or when technical reasons demand its application, the ecological issues should be priority.

\section{References}

[1] YUN, W. et al (2012). Oxidation of Aluminium Alloy Melts and Inoculation by Oxide Particles. Trans. Indian Inst. Met., October, pp. 1-9

[2] FIORESE E et al (2015). New Classification of Defects and Imperfections for Aluminium Alloy Castings. International Journal of Metalcasting, Vol. 9, Issue 1, pp. 55-66

[3] SHORT T. (2003). The Identification and Prevention of Defects on Anodized Aluminium Parts. Metal Finishing Information Services Ltd.

[4] FRIEDRICH B. (2015). Understanding of Inclusions - Characteristics, Interaction and Boundaries of Removability with Special Focus on Aluminium Metals. IME, WWTH, Aachen University, September

[5] Machining of Aluminium and Aluminium Alloys (1989). ASM Handbook, ASM International ${ }^{\circledR}$, Vol. 16: Machining, ASM Handbook Committee, pp. 761-804

[6] Carrilero, M. S., Marcos, M. (1996). On the Machinability of Aluminium and Aluminium Alloys.
Journal of the Mechanical Behaviour of Materials, Vol. 7, No. 3, pp. 179-193

[7] SALES, W. F., DINIZ, A. E., MACHADO, Á. R. (2001). Application of Cutting Fluids in Machining Processes. Journal of the Brazilian Society of Mechanical Sciences, Vol. 23, No. 2, Rio de Janeiro.

[8] HRONEK, O., ZETEK, M., BAKŠA, T., ADÁMEK, P. (2017). Quality of the Cutting Tool Microgeometry for Machining Aluminium Alloys. Manufacturing Technology, Vol. 17, No. 4, pp. 463-469

[9] MAJERNÍK, J., DUBOVSKÁ, R., BAŠKA, I., JAMBOR, J. (2018). Experimental Investigation and Measurement of Surface Roughness and Cutting Forces while Turning $\mathrm{AlCu} 3 \mathrm{MgMnPb}$ Aluminium Alloy. Manufacturing Technology, Vol. 18, No. 1, pp. 66-71

[10] MARTINOVSKÝ, M., MÁDL, J. (2016). The Effect of Different Modifiers in AlSi7Mg0.3 Alloy on Built-up Edge Formation in Machining. Manufacturing Technology, Vol. 16, No. 1, pp. 173-178

[11] QU, S., SUN, F., ZHANG, L., LI, X. (2014). Effects of cutting parameters on dry cutting of aluminium bronze alloy. International Journal of Advanced Manufacturing Technology, Vol. 70, No. 1-4, pp. 669 - 678. Springer

[12] YUSUF, M., ARIFFIN, M. K. A., ISMAIL, N., SULAIMAN, S. (2013). Chip formation and surface roughness in dry machining of aluminium alloys. Advanced Science Letters, Vol. 19, No. 8, pp. $2343-2346$.

[13] BATZER, S., SUTHERLAND, J. (1998). The Dry Cure for Coolants Ills. Cutting Tool Engineering, June, pp. 334-44

[14] GRAHAM, D. (2000). Dry Out. Cutting Tool Engineering, March, pp. 56-65. 